\title{
Study of gender determination in living adult male and female subjects by evaluating the size of sternum about north Indian population
}

\author{
S V Sharma ${ }^{1, *}$, Virendra Atam², Navneet Kumar ${ }^{3}$, Nilesh Sharma ${ }^{4}$, Isha Atam ${ }^{5}$, H. B. Sharma ${ }^{6}$ \\ ${ }^{\mathbf{1}}$ Resident, ${ }^{\mathbf{2}, 3}$ Professor and Head, ${ }^{\mathbf{4}}$ Laboratory Assistant, ${ }^{\mathbf{5}}$ Medical Officer, ${ }^{\mathbf{1}, 3}$ Dept. of Anatomy, ${ }^{\mathbf{2 , 4 5}}$ Dept. of Medicine, King George's \\ Medical University, Lucknow, Uttar Pradesh, India \\ *Corresponding Author: S V Sharma \\ Email: sv_sharmakgmu@ @rediffmail.com
}

\begin{abstract}
Introduction: The gender determination from the skeletal remains is of very much interest in the field of medical science. Ashley GT 1956b formulated the 149 rule according to which a male sternum exceeded $149 \mathrm{~mm}$ in length whereas the female sternum was less than $149 \mathrm{~mm}$. on the basis of previous researcher I have been planned to verify the external data and establish them in reference to population in and around Lucknow. With the help of this study we were distinguishes the male and female sternum bone in north zone of India as well as Uttar Pradesh.

Materials and Methods: The above mentioned measurements have been further use to calculate various sternal dimensions and indices according to the technique described by Ashley. Each linear measurement has been taken thrice on the anatomical position of the sternum using Mitutoyo-digital vernier calipers to the nearest millimeter with precision of $0.01 \mathrm{~mm}$.

Discussion: This study was fully supported the previous researchers, who has done the work in morphometry of sternum bone in cadaver and skeletal of human, because they told that the sterna has distinguish in different zone of India, as well as it is shorter than European country.

Conclusion: The comparison of mean length of manubrium, mesosternum and sternum ranged from 40.39-71.31 mm, 83.49-129.97 mm and 150.21-170.39 mm respectively in adult male (16-60yrs) where as in adult female ranged from 23.79-60.35 $\mathrm{mm}, 68.33-122.42 \mathrm{~mm}$ and 116.36-148.92 $\mathrm{mm}$ respectively.
\end{abstract}

Keywords: Sternum bone, Gender determination, Length of manubrium, Length of mesostenum.

\section{Introduction}

Sex determination of unidentified skeletal remains very in forensic or archeological situations, is one of the prime tasks of experts like forensic anthropologists and bioarcheologists involved in such examinations. ${ }^{1}$ In case of mass-disasters such as armed conflicts, terrorist massacres, aeroplane crashes, war related crimes etc., when badly decomposed, mutilated or damaged human remains consisting of only a few bones or their fragments are recovered from the site, it becomes crucial to establish the biological identity, especially the sex of a missing individual $^{2}$ Though, a number of bones such as pelvis, skull femur etc., ${ }^{3,4}$ have contributed significantly to this endeavor, these sex-specific or sex indicative bones are not always found at such scenes. In such situations, forensic anthropologists and bioarcheologists have to depend on less sexually dimorphic elements of human skeleton such as sternum. ${ }^{5,6}$

Ashley GT -1956b formulated the 149 rule according to which a male sternum exceeded $149 \mathrm{~mm}$ in length whereas the female sternum was less than $149 \mathrm{~mm}$. This rule was applicable to $77.6 \%$ males and $80.4 \%$ females for European sterna. ${ }^{11}$

The gender determination from the skeletal remains is of very much interest in the field of medical science and law. The bones are more resistant to the putrification process that makes it important to study, which in turn helps identify the gender determination criteria. Next to pelvis, human skull is regarded as the most accurate indicator of the $\operatorname{sex}^{7}$ but when these bones are missing; recent findings have suggested that sternum and manubrium can act as valuable specimens. ${ }^{8,4}$

In India, various researchers have presented their work on the sternum regarding sex determination. ${ }^{9}$ This study has been planned to verify the existrnal data and establish them in reference to population in and around Lucknow. Since the study was conducted in the people of Lucknow, and subjects were selected only from in and around the Lucknow as the race and built may affect the dimensions of the sternum. With the help of this study we were distinguishes the male and female sternum bone in north zone of India as well as Uttar Pradesh.

\section{Materials and Methods}

This study has been conducted on the total 100 subjects, 50 female (16-60yrs) and 50 male (16-60yrs) of healthy people (Living adult subjects) from general population of north India as well as in and around the department of anatomy at King George's Medical University U P Lucknow. After obtaining ethical clearance and informed consent form, the living subjects have been recruited from the healthy staff members of OPD, department of medicine, pediatrics and Obs \& gynecology at King George's Medical University U P Lucknow. All the living subjects have been well informed about the nature of study. To prevent discrimination, living subjects have recruited for our study fulfilling inclusion criteria (male and female, age 16 to 60 years, BMI less than 25 and no history of chronic disease, at least 1 years tenure, no use of medication other than analgesics during the month preceding data collection). The living subjects have been explained the procedure of study. 
For the morphometry of the sternum, following measurements have been taken in to consideration

Length of Manubrium: It has been measured from the centre of suprasternal notch to the centre of the manubriosternal junction in mid sagittal plane.

Length of Mesosternum: It has been measured from the centre of manubrio-sternal junction to the centre of sternoxiphoid junction in the mid sagittal plane.

Total Length of Sternum: It has been measured from the centre of jugular notch to xiphoid process in the mid sagittal plane.

The above mentioned measurements have been further use to calculate various sternal dimensions and indices according to the technique described by Ashley. Each linear measurement has been taken thrice on the anatomical position of the sternum using Mitutoyo-digital vernier calipers to the nearest millimeter with precision of $0.01 \mathrm{~mm}$, according to definitions presented in and their average was recorded. ${ }^{10}$

\section{Result}

Basic Characteristics: The present study deals with sex determination through measurement of human sternum in Lucknow city of Uttar Pradesh (U.P.). The primary outcome measures of the study were length of manubrium, length of mesosternum and length of sternum measured in millimeter $(\mathrm{mm})$. Besides that actual age (yrs), height $(\mathrm{cm})$, weight $(\mathrm{kg})$, chest circumference $(\mathrm{cm})$, waist circumference and hip circumference $(\mathrm{cm})$ were also noted.

I. Male 16-60yrs: The basic characteristics of 16-60yrs males are summarized in Table 1 . The mean length of manubrium, mesosternum and sternum ranged from 40.39$71.31 \mathrm{~mm}, 83.49-129.97 \mathrm{~mm}$ and 150.21-170.39 $\mathrm{mm}$ respectively with mean $58.97 \pm 6.68 \mathrm{~mm}, 103.74 \pm 8.42 \mathrm{~mm}$ and $162.70 \pm 5.70 \mathrm{~mm}$ respectively and median $59.16 \mathrm{~mm}$, $104.29 \mathrm{~mm}$ and $163.52 \mathrm{~mm}$ respectively.

II. Female 16-60yrs: The basic characteristics of 16-60yrs females are summarized in Table 2. The mean length of manubrium, mesosternum and sternum ranged from 23.79$60.35 \mathrm{~mm}, 68.33-122.42 \mathrm{~mm}$ and 116.36-148.92 $\mathrm{mm}$ respectively with mean $48.38 \pm 5.71 \mathrm{~mm}, 89.55 \pm 10.81 \mathrm{~mm}$ and $137.93 \pm 8.70 \mathrm{~mm}$ respectively and median $48.77 \mathrm{~mm}$, $90.11 \mathrm{~mm}$ and $139.47 \mathrm{~mm}$ respectively.

Comparison between Female vs. Male- 16-60yrs: The comparison of mean length of manubrium, mesosternum and sternum between 16 to 60yrs female and male is summarized in Table 3 and also depicted in Fig. 4 to 6 respectively. Comparing the mean length of manubrium, mesosternum and sternum between two groups, Student's t test showed significantly different and higher length of manubrium $(18.0 \%)(48.38 \pm 5.71$ vs. $58.97 \pm 6.68, \mathrm{t}=8.52$, $\mathrm{p}<0.001)$, mesosternum $(13.7 \%)(89.55 \pm 10.81$ vs. $103.74 \pm$ $8.42, \mathrm{t}=8.98, \mathrm{p}<0.001)$ and sternum $(15.2 \%)(137.93 \pm 8.70$ vs. $162.70 \pm 5.70, \mathrm{t}=16.84, \mathrm{p}<0.001)$ in males as compared to females.

Table 1: Basic characteristics of 16-60yrs males

\begin{tabular}{|l|c|c|c|c|c|c|c|}
\hline \multicolumn{1}{|c|}{ Variable } & N & Min & Max & Mean & SD & SE & Median \\
\hline Age $(\mathrm{yrs})$ & 50 & 17.00 & 60.00 & 39.58 & 12.40 & 1.75 & 39.00 \\
\hline Height $(\mathrm{cm})$ & 50 & 157.28 & 189.34 & 167.47 & 6.62 & 0.94 & 165.43 \\
\hline Weight $(\mathrm{cm})$ & 50 & 40.58 & 95.72 & 63.94 & 10.11 & 1.43 & 63.48 \\
\hline BMI $\left(\mathrm{kg} / \mathrm{m}^{2}\right)$ & 50 & 15.60 & 28.80 & 22.77 & 3.06 & 0.43 & 22.57 \\
\hline Chest circumference $(\mathrm{cm})$ & 50 & 76.49 & 114.46 & 90.77 & 8.57 & 1.21 & 90.15 \\
\hline Waist circumference $(\mathrm{cm})$ & 50 & 68.29 & 120.28 & 87.08 & 11.23 & 1.59 & 86.98 \\
\hline Hip circumference $(\mathrm{cm})$ & 50 & 80.37 & 113.01 & 92.88 & 7.31 & 1.03 & 93.21 \\
\hline Length of manubrium $(\mathrm{mm})$ & 50 & 40.39 & 71.31 & 58.97 & 6.68 & 0.95 & 59.16 \\
\hline Length of mesosternum mm) & 50 & 83.49 & 129.97 & 103.74 & 8.42 & 1.19 & 104.29 \\
\hline Length of sternum $(\mathrm{mm})$ & 50 & 150.21 & 170.39 & 162.70 & 5.70 & 0.81 & 163.52 \\
\hline
\end{tabular}

Table 2: Basic characteristics of 16-60yrs females

\begin{tabular}{|l|c|c|c|c|c|c|c|}
\hline Variable & N & Min & Max & Mean & SD & SE & Median \\
\hline Age $(\mathrm{yrs})$ & 50 & 17.00 & 55.00 & 35.70 & 8.32 & 1.18 & 36.50 \\
\hline Height $(\mathrm{cm})$ & 50 & 142.39 & 165.49 & 154.24 & 5.72 & 0.81 & 154.56 \\
\hline Weight $(\mathrm{cm})$ & 50 & 35.46 & 85.19 & 61.46 & 10.63 & 1.50 & 62.54 \\
\hline BMI $\left(\mathrm{kg} / \mathrm{m}^{2}\right)$ & 50 & 14.96 & 32.20 & 25.81 & 4.11 & 0.58 & 26.14 \\
\hline Chest circumference $(\mathrm{cm})$ & 50 & 75.29 & 116.16 & 96.21 & 9.03 & 1.28 & 96.83 \\
\hline Waist circumference $(\mathrm{cm})$ & 50 & 58.18 & 118.28 & 96.16 & 12.59 & 1.78 & 98.36 \\
\hline Hip circumference $(\mathrm{cm})$ & 50 & 80.19 & 117.87 & 100.89 & 8.41 & 1.19 & 100.41 \\
\hline Length of manubrium $(\mathrm{mm})$ & 50 & 23.79 & 60.35 & 48.38 & 5.71 & 0.81 & 48.77 \\
\hline Length of mesosternum $(\mathrm{mm})$ & 50 & 68.33 & 122.42 & 89.55 & 10.81 & 1.53 & 90.11 \\
\hline Length of sternum $(\mathrm{mm})$ & 50 & 116.36 & 148.92 & 137.93 & 8.70 & 1.23 & 139.47 \\
\hline
\end{tabular}


Table 3: Comparison of length of manubrium, mesosternum and sternum (Mean $\pm \mathrm{SD}$, n=50) between 16 to $60 \mathrm{yrs}$ female and male

\begin{tabular}{|c|c|c|c|c|}
\hline Variable & Female & Male & t value & p value \\
\hline Length of manubrium (mm) & $48.38 \pm 5.71$ & $58.97 \pm 6.68$ & 8.52 & $<0.001$ \\
\hline Length of mesosternum (mm) & $89.55 \pm 10.81$ & $103.74 \pm 8.42$ & 7.32 & $<0.001$ \\
\hline Length of sternum (mm) & $137.93 \pm 8.70$ & $162.70 \pm 5.70$ & 16.84 & $<0.001$ \\
\hline
\end{tabular}

\section{Length of manubrium ( $\mathrm{mm})-16$ to $60 \mathrm{yrs}$}

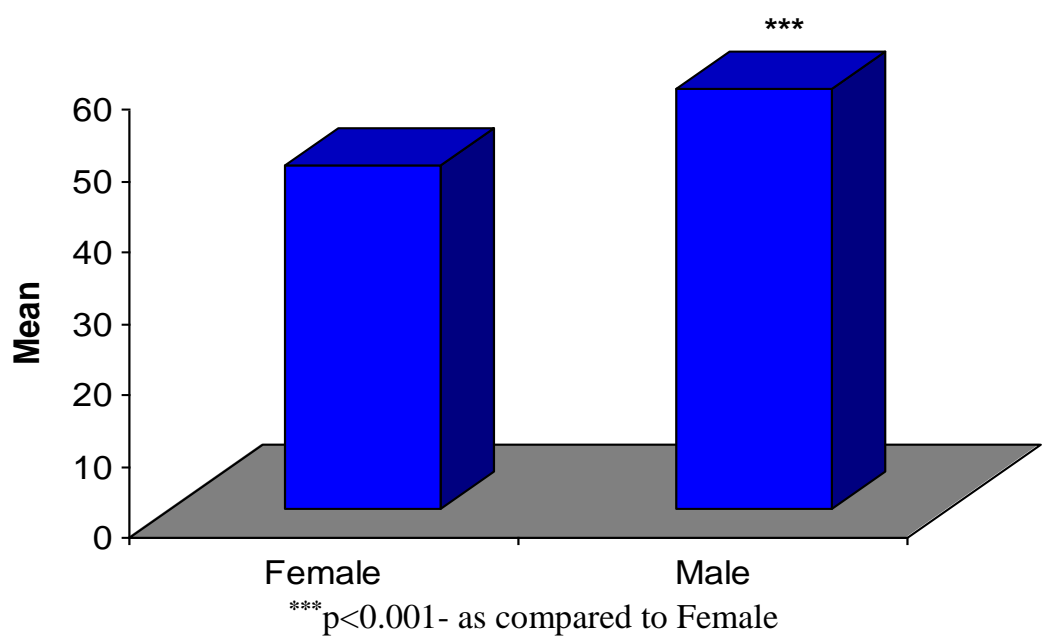

Fig. 4: Comparison of length of manubrium between 16 to $60 y$ rs females and males

\section{Length of mesosternum ( $\mathrm{mm})-16$ to $60 \mathrm{yrs}$}

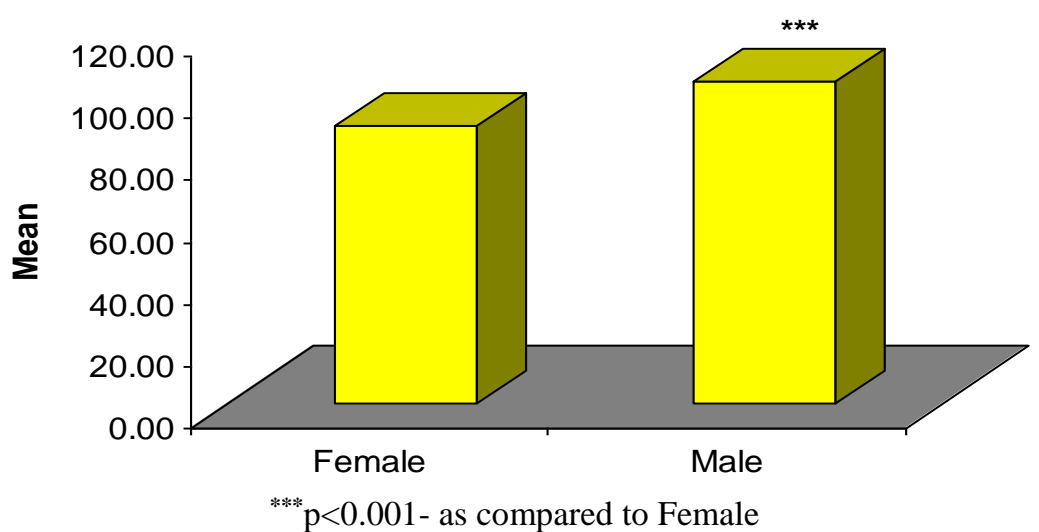

Fig. 5: Comparison of length of mesostermum between 16 to $60 y$ rs females and males 


\section{Length of sternum ( $\mathrm{mm})-16$ to 16 yrs}

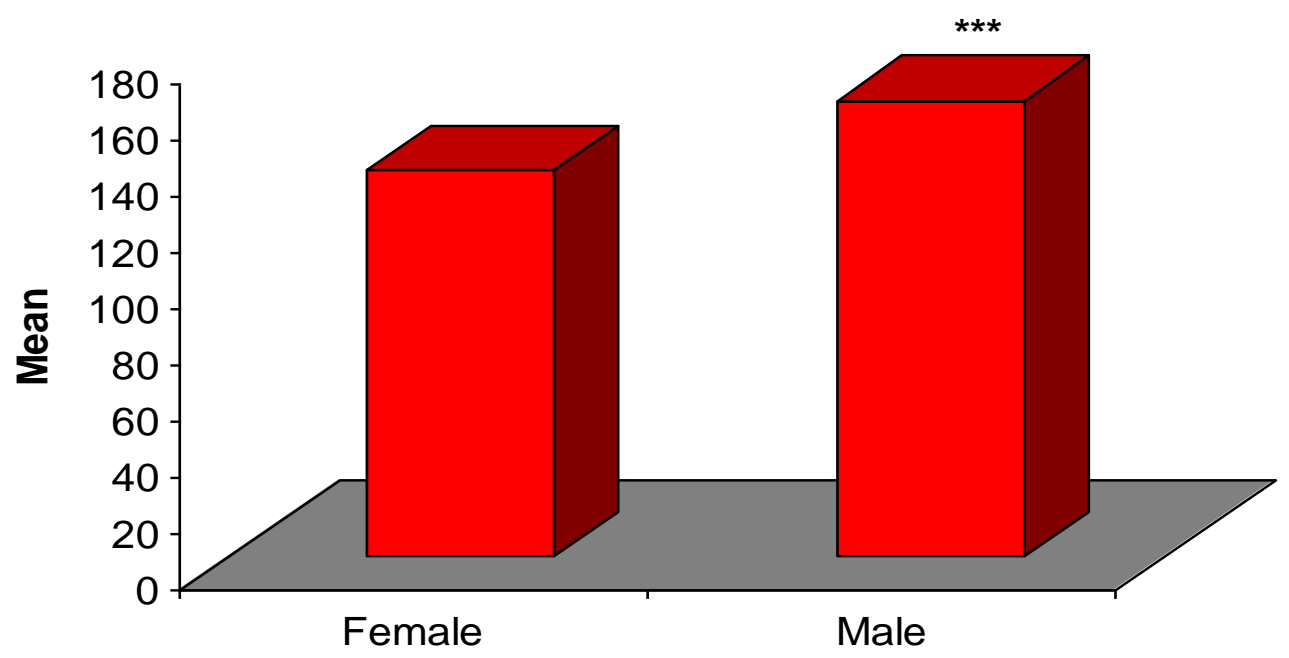

**** $\mathrm{p}<0.001-$ as compared to Female

Fig. 6: Comparison of length of sternum between 16 to 60yrs females and males.

\section{Discussion}

The aim of the present study was to evaluate the Sex determination through measurement of human sternum in Lucknow city of Uttar Pradesh, India. Results from our study revealed that body weight, BMI, and abdominal circumference were in normal range. The findings suggest that osteometric evaluation of the sternum can be an effective method for identification of sex in the Lucknow population as well as Uttar Pradesh.

Comparison between Female vs. Male- 16-60yrs: The comparison of mean length of manubrium, mesosternum and sternum between 16 to 60yrs female and male is Comparing the mean length of manubrium, mesosternum and sternum between two groups, Student's t test showed significantly different and higher length of manubrium $(18.0 \%)(48.38 \pm 5.71$ vs. $58.97 \pm 6.68, \mathrm{t}=8.52, \mathrm{p}<0.001)$, mesosternum (13.7\%) (89.55 \pm 10.81 vs. $103.74 \pm 8.42$, $\mathrm{t}=8.98, \mathrm{p}<0.001)$ and sternum $(15.2 \%)(137.93 \pm 8.70$ vs. $162.70 \pm 5.70, \mathrm{t}=16.84, \mathrm{p}<0.001)$ in males as compared to females.

According to observation and result in my present study it was fully supported the previous researchers, who has done the work in morphometry of sternum bone in cadaver and skeletal of human, because they told that the sterna has distinguish in different zone of India, as well as it is shorter than European country.

On the basis of above observation and result we can discus that ${ }^{1}$ [Ashley GT -1956b] got $52.2 \mathrm{~mm}$ for males and $47.9 \mathrm{~mm}$ for females. ${ }^{11}$ obtained $51.73 \mathrm{~mm}$ for males and $48.42 \mathrm{~mm}$ for females, which agreed with our findings of $58.97 \mathrm{~mm}$ for males and $48.38 \mathrm{~mm}$ for females. From the parameters used in this study, the length of the manubrium distinguishes $18.0 \%$ males is longer than females. This observation indicates that the difference between the average length of the male and female manubrium is 8.52 $\mathrm{mm}$, which is statistically significant $(\mathrm{P}<0.001)$ with the length of the male manubrium being longer than that of the female. In the human sternum, which is a highly sexually dimorphic bone, only the mesosternum length of the sternum was seen to be highly useful in distinguishing a male from a female sternum.

According to 149 rules, $^{12}$ the male length of mesosternum was $101.3 \mathrm{~mm}$ and $79.9 \mathrm{~mm}$ for females respectively. His findings were supported by ${ }^{13}$ and. ${ }^{14}$

\section{Conclusion}

The basic characteristics of 16-60yrs in males and female like age, height, weight, chest circumference, waist circumference and hip circumference and BMI was in normal range respectively. The comparison of mean length of manubrium, mesosternum and sternum ranged from 40.39-71.31 mm, 83.49-129.97 $\mathrm{mm}$ and 150.21-170.39 $\mathrm{mm}$ respectively in adult male (16-60yrs) where as in adult female ranged from $23.79-60.35 \mathrm{~mm}, 68.33-122.42 \mathrm{~mm}$ and 116.36-148.92 $\mathrm{mm}$ respectively.

This study concluded that the male sternum is longer than female sternum. This conclusion will provide the help to distinguish factors for medico-legal studies where examination of human skeleton is obviously of greatest importance for identification purposes.

Thus the present results in my study was provide full support, study done by Ashley GT-1956b formulated the 149 rule, according to which a male sternum exceeded $149 \mathrm{~mm}$ in length whereas the female sternum was less than $149 \mathrm{~mm}$.

\section{Statistical Analysis}

Data were summarized as Mean \pm SD (standard deviation), range ( $\min$ to $\max$ ) and median. Groups were compared by independent Student's t test. Pearson 
correlation was done to assess association between variables. A two-tailed $(\alpha=2) \quad \mathrm{p}<0.05$ was considered statistically significant. Analyses were performed on SPSS software (windows version 21.0). The statistical analysis has been done by Dr. M.P. Negi, from Central Drug Research Institute (CDRI) Lucknow.

\section{Acknowledgement}

The authors are grateful to all subjects who participated in this study. I would like to thanks Dr. M.P. Negi, Statistician in Central Drugs Research Institute (CDRI), Lucknow for his Statistical analysis and cooperation, and I would like to give specially Thanks Dr. Navneet Kumar, Professor \& Head, department of Anatomy, King George's Medical University, U.P., Lucknow for developing this hypothesis, cooperation, and conducting this research work.

\section{Conflict of Interest: None.}

\section{References}

1. Ashley GT. A comparison of human and anthropoid mesosterna. Am J Phys Anthropol 1956;14(3):449-461.

2. Mc Cormick WF, Stewart JH, Langford LA. Sex determination from chest plate roentgenograms. Am J Phys Anthropol 1985;68:173-195.

3. Selthofer R, Nicolic V, Mrcela T, Radic R, Leksan I, Rudez I, Selthofer K. Morphometric analysis of the sternum. Coll Antropol 2006;30:43-47.

4. Osunwoke EA, Gwunireama IU, Orish CN, Ordu KS, Ebowe I. A study of sexual dimorphism of the human sternum in the southern Nigerian population. J Appl Biosci 2010;26:16361639.

5. Ramadan M, Turkmen N, Dolgan NA, Gokharman D, Menezes M, Kacar M, Kosar U. Sex determination from measurements of the sternum and fourth rib using multislice computed tomography of the chest. Forensic Sci Int 2010;197:120.e1-5.
6. Macaluso PJ. The efficacy of sternal measurements for sex determination in South African blacks. Forensic Sci Int 2010;202:111e.111e.7.

7. Macaluso PJ, Lucena J. Estimation of sex from sterna dimensions derived from chest plate radiographs in contemporary Spaniards. Int J Legal Med 2014;128(2):389395.

8. Dwight $\mathrm{T}$. The sternum as an index of sex and age. $J$ Anat 1881;15:327-330

9. Singh J, Pathak RK, Singh D. Morphometric sex determination from various sternal widths of Northwest Indian sternums collected from autopsy bones: Egypt J Forensic Sci 2002;2(1):18-28.

10. Bass WM. Human Osteology: A Laboratory and Field Manual of the Human Skeleton ( $3^{\text {rd }}$ Ed.). Missouri Archaeological Society Special Publications, Columbia, Missouri. 1987: p. 112

11. Jit I. Bakshi, Time of fusion of the human mesosternum with manubrium and xiphoid process. Indian J Med Res 1986;82:322-327.

12. Ashley GT, The human sternum - the influence of sex and age on its measurement. J Forensic Med 1956b;3:27-43.

13. Camps FE. Editor Gradwohl's legal medicine. 3rd ed. Bristol. John Wright \& sons Ltd; 1976. p. 110.

14. Bass WM. Human Osteology: A Laboratory and Field Manual of the Human Skeleton ( $3^{\text {rd }}$ Ed.). Missouri Archaeological Society Special Publications, Columbia, Missouri. 1987: p. 112.

How to cite this article: Sharma SV, Atam V, Kumar N, Sharma N, Atam I, Sharma HB. Study of gender determination in living adult male and female subjects by evaluating the size of sternum about north Indian population. Indian J Anat Surg Head Neck Brain 2018;4(4):118-122. 